Article

\title{
Assessing the Openness and Conviviality of Open Source Technology: The Case of the WikiHouse
}

\author{
Christina Priavolou ${ }^{1}$ and Vasilis Niaros ${ }^{2, *}$ \\ 1 Ragnar Nurkse Department of Innovation and Governance, Tallinn University of Technology, \\ Akadeemia street 3, 12618 Tallinn, Estonia \\ 2 Internet Interdisciplinary Institute (IN3), Universitat Oberta de Catalunya, Av. Carl Friedrich Gauss, 5, \\ 08860 Castelldefels, Barcelona, Spain \\ * Correspondence: vniaros@uoc.edu; Tel.: +30-6949-202-030
}

Received: 9 August 2019; Accepted: 28 August 2019; Published: 30 August 2019

check for updates

\begin{abstract}
The housing crisis has received growing interest from academia, industry, and policymakers. Open construction systems have emerged as a promising solution to achieve long-term social, economic, and environmental sustainability. In this paper, extensive fieldwork was conducted to investigate a case of an open construction system, namely, the WikiHouse Den Bosch. The research framework builds on a combined view of two main concepts: "conviviality" and "openness". The aim is to provide an in-depth understanding of the relationship between these two aspects and the literature regarding "Design Global Manufacture Local". The analysis showed that conviviality and openness are complex and context-specific factors. The paper concludes by outlining the need for an "institutionalized conviviality" to open up new pathways for future practice to address sustainability issues.
\end{abstract}

Keywords: conviviality; openness; commons; open hardware; WikiHouse; open innovation

\section{Introduction}

With increasing access to information and communication technologies (ICT), the commons, and particularly the production of digital commons is blossoming [1]. Commons-based peer production (CBPP) surfaced as a way of self-organizing communities towards value creation [1,2]. By placing the users' needs and values at the center of attention, globally networked communities use and modify the recorded information to produce customized solutions that best serve their needs. The communities then publicly share their products and offer feedback to enrich and strengthen the existing collective knowledge. The free encyclopedia Wikipedia and free/open-source software initiatives such as the GNU/Linux operating system and the Wikipedia encyclopedia exemplify this new mode of production.

The emerging open source hardware (OSH) phenomenon is transferring open source software principles into the physical realm [3]. Open design and distributed manufacturing have been enabled through networked "makerspaces" [4,5]. Such community-driven places are equipped with desktop manufacturing technologies including digital tools (e.g., three-dimensional (3D) printers, computer numerically controlled (CNC) machines, and low-tech tools) and utilize inclusive decision-making processes to manage common resources [6,7]. Thus, collaboration and access to shared infrastructures are fostered, offering space for people to socialize and co-create [5].

The Design Global, Manufacture Local (DGML) approach has emerged as a production model that focuses on localized production settings via a network of distributed makerspaces [8,9]. It builds on the convergence of global digital commons (i.e., knowledge, software, and design) with local manufacturing technologies, by taking into account the surrounding biophysical conditions [9]. The reduction of transportation costs and the expected low environmental impact of locally produced 
solutions are considered as significant benefits of this model [4]. Furthermore, on-demand production, sharing physical and digital infrastructures as well as the production of solutions towards a common good rather than profit maximization are key components of the DGML model [9].

Notwithstanding the positive dynamics of the DGML approach in the production of tangible artifacts, concerns have been raised with respect to: (i) the existence of a comprehensive shared documentation that renders a hardware product "open" [10]; and (ii) the level of autonomy the user has while developing and maintaining that product. To explore such issues, we looked at the construction sector. Considering the low productivity rates and unsustainable practices unveiled through the bursting of the housing bubble [11], the potential to produce more convivial houses through community-driven processes was explored.

By applying DGML principles in the construction sector, we refer to open construction systems as a potentially sustainable approach in housing provision. Through community-driven practices, pressing issues related to the lack of transparent and sustainable processes could be addressed [12]. The embedded modularity of such systems, together with their momentum to provide affordable housing in a collaborative and convivial way, is gradually increasing their social impact, affecting large parts of the Western and non-Western world [13].

In line with the DGML model, open construction systems attempt to provide affordable housing in a creative and convivial way. However, safety issues related to the construction of a DGML house have been identified [12]. Overcoming such issues will potentially inaugurate a new paradigm in building houses where the users feel in control of constructing and maintaining their houses.

An instrumental case study was thoroughly examined to assess certain features of an open construction system, that of a WikiHouse [14]. These features are associated with advantages that refer to the conviviality as well as the drawbacks that pertain to the openness degree of the WikiHouse technology. The latter has been claimed to inaugurate a model of open-source practice towards the democratization of the construction process [15].

In this article, the comprehensiveness of the published data and the relevant practices will be discussed for a specific WikiHouse technology. Through evidence-based analysis of the relevant dynamics, we will shed light on the conviviality and the openness potential of a WikiHouse. The aim is to critically assess the conviviality potential of a DGML artefact and examine the role of openness in enhancing DGML features. An in-depth understanding of the relationship between openness and conviviality as well as their interrelation with the DGML approach for producing technological solutions will be explored.

The rest of the paper is organized as follows. Section 2 describes the theoretical background associated with the DGML approach and the concepts of conviviality and openness. Section 3 provides information on the methods used and the selected case study, while Section 4 reflects on the previous sections by analyzing and summarizing the connection between the above-mentioned concepts, while Section 5 presents our conclusions and provides recommendations for future research.

\section{Theoretical Framework}

\subsection{Design Global, Manufacture Local in a Nutshell}

The DGML approach aims to create communities whose incentives and relationships differ from the dominant mass production model [16]. Utilizing democratic procedures and participatory processes, such communities produce and control technologies locally. The produced designs are uploaded, shared, and freely available to further modify and/or upgrade. Thus, innovation is accelerated, while customized low-cost solutions can be developed and maintained by non-experts according to their preferences. Hence, new ways of value creation are inaugurated by utilizing human creativity, removing hierarchical barriers of organizing production, and deprioritizing monetary motives.

The conventional industrial model of mass production differs from the DGML model mainly in terms of scale, incentives, and collaborative features. Focusing on bottom-up value creation patterns, 
participatory processes are developed by users who asynchronously collaborate and share common infrastructure. DGML projects produce solutions strengthened by the power of collective intelligence and cooperation [17]. Sharing practices and mutualization of digital (including design and software applications) and physical (including shared machinery in makerspaces) resources are utilized to produce commons-based technologies through democratic decision-making processes.

Another aspect of the DGML model is on-demand local production. Environmental sustainability is fostered, thus reducing the need for the transportation of raw materials and machines and the associated environmental costs [4]. The embedded modularity in DGML artifacts enables the development of structures that can be easily replicated, modified, and customized by separating and recombining smaller parts (modules) of the whole system. Thus, people can work on different modules in an independent and distributed way, making adaptable structures according to their needs.

Finally, following the industrial production paradigm, planned obsolescence tends to force consumers to purchase new or upgraded versions to maintain the functionality of their products [18]. Removing planned obsolescence and profit-oriented incentives through commons-based initiatives signify that such communities prioritize environmental, social, and economic justice [19]. Although no sound empirical evidence has assessed the sustainability degree of a DGML artifact, it is considered that such communities design and produce solutions towards sustainability [16].

\subsection{Defining "Conviviality"}

Through the analysis of the features of DGML, it becomes evident that conviviality constitutes a core element of this productive model. Ivan Illich [20] introduced the concept of conviviality to emphasize the importance of creativity, autonomy, decentralization, and the construction of technology in a social manner [20-22]. In modern industrial production, people rely on specialists to produce the necessary tools to satisfy their needs. In contrast, conviviality fosters the control of the use of resources and promotes friendly relationships and reciprocity between individuals and their environment [23,24].

Moving away from the planned obsolescence of the industrial paradigm, conviviality provides a new approach to rethink the way of designing products, services, and associated technologies [25]. Such designs empower users to grasp a technological product, experiment, and adjust it.

Illich spoke of "tools for conviviality" that "foster conviviality to the extent to which they can be easily used, by anybody, as often or as seldom as desired, for the accomplishment of a purpose chosen by the user" [20] (p. 22). Although there is no fixed definition of "convivial tools", Illich [20] has formulated a set of criteria/conditions that qualify them: (i) convivial tools are easy to use or require learning by doing (i.e., no preparatory education or certification by specialists is demanded to use the tool); (ii) they are at the user's judgment regarding whether and when they are used; and (iii)s they are adapted to the user's preferences and not the other way around [20,26].

A distinctive example of a convivial tool is the bicycle. As a relatively easy tool to comprehend, repair, and adjust, the bicycle can be considered as a highly convivial tool [23]. New bikes can be produced by reusing spare parts, while several modifications are possible such as adding a child seat or an electric motor based on the user's preferences. Furthermore, individuals can autonomously transport themselves, hence decreasing their reliance on other expensive transportation means [23].

It should be noted that conviviality is not applied only to low-tech tools, but is also relevant to more sophisticated technologies. Highly complex OSH products combine several technologies that consist of different parts and are designed to meet demanding needs [27]. Still, all tools have a conviviality potential, provided they meet the requirements mentioned earlier in this section. However, the distinction between "convivial technologies" and "convivial tools" should be highlighted. While Illich [20] spoke of "tools", referring not only to artifacts but also to rationally designed institutions such as schools, other scholars have shed light on different aspects of technology. These might entail processes like the design phase of an artifact as well as the relevant know-how concerning the manufacturing, use, and maintenance of a product [28,29]. 
Indeed, Illich $[18,20]$ concentrated on the use of tools, without considering the production phase. The latter was taken into account by Andrea Vetter [30], who developed the "Matrix of Convivial Technologies". This matrix aims to define and measure the conviviality potential of a technological artifact during several phases of its development process through empirical research (see Section 3.1).

Although conviviality is seen as an essential factor while practicing DGML, it might not be sufficient to secure the successful realization of this productive model. Hence, this article also explored the concept of openness, which is a core value in the DGML setting.

\subsection{The Concept of "Openness"}

Echoing Balka et al. [3] and von Hippel [31], openness pertains to (i) transparency (freedom to study); (ii) accessibility (freedom to edit/modify); (iii) replicability (freedom to make); and (iv) commercial usability (freedom to distribute) of information required for a product's sustainable development. These four criteria are respectively met when: (i) Computer-aided design files and schematics are published; (ii) all published information is editable, therefore enabling others to participate in the design process; (iii) the bill of materials and assembly instructions are published; and (iv) the commercial usage and free redistribution of the published information are permitted via relevant licenses [10].

Furthermore, Aitamurto et al. [32] focused on two aspects of openness related to the process (whether it is open or closed), and the product (whether the outcome is open or closed). However, defining a work as open or closed is rarely a binary decision. The spectrum of openness is quite broad, encompassing several degrees of openness. At one end, the work is "closed" if the creator excludes others from its use, while, at the other end, an "open" work is available to and modifiable by all. Hence, the question should be "how open" a process or a product is [33].

Attributes such as transparency, accessibility, and replicability determine the degree of openness of a particular work. Nevertheless, restrictions on observing, modifying, or replicating a work may be applied including the exclusion of commercial use or a membership requirement [3]. Intellectual property rights in licenses may be used to set the degree of a product's openness [34].

It is generally acknowledged by both scholars and practitioners that sharing a piece of hardware online is much more complicated than sharing a piece of software, while software is digital by nature, hardware may require more sophisticated tools to be displayed such as modeling and design tools [35]. Furthermore, based on the evaluation of $20 \mathrm{OSH}$ projects that included both hardware and software components, Balka et al. [3] argued that hardware components were less documented than those of software. This fact raises the question of whether a poorly documented piece of hardware is open source or not.

Through the increased utilization of ICT, the benefits of openness are becoming more evident and are likely to grow [33]. Once the design of a product is openly shared, billions of people have access to it. This diffusion enhances the reputation of the product, while often positive network effects are applied [36]. Additionally, those who can manipulate the design can improve or suggest improvements to the product, benefiting both the innovator and users [33,34]. Finally, keeping a design closed may be much more costly when compared to leaving it open to others to access and use [34].

These benefits, along with the power and ethics of openness, have led to the creation of a strong brand that is universally admired and respected. Users have a growing desire to experience transparency in their services, so openness is becoming a key feature [37]. Hence, many organizations wish to associate with it. However, if an organization cannot adjust its business model to become open, then it redefines the meaning of "openness" to fit their practices. Members of the open community usually recognize such behaviors and describe them as openwashing (i.e., "to spin a product or company as open, although it is not.") [38]. 


\section{The Case of the WikiHouse Den Bosch}

The WikiHouse Den Bosch is an ongoing initiative in the Netherlands. It aims to respond to the housing crisis via the development of innovative forms of housing. As explained in this section, our case study was chosen since it exemplifies the DGML model and allowed us to explore the conviviality and openness dynamics of the WikiHouse technology.

\subsection{Materials and Methods}

Given the importance of mixed research approaches and data gathering techniques in case study research [39], several methods were implemented to achieve our specific goals (see Figure 1). First, personal communication with key informants [40] was useful to obtain first-hand information on the WikiHouse technology apropos the Dutch context as well as the development of the case of WikiHouse Den Bosch. Four interviews, supplemented with informal discussions with key stakeholders of the initiative, took place over three weeks in the Netherlands in October 2018. Semi-structured interviews were selected, offering the opportunity to the interviewees to discuss what they deemed most important and reach a common understanding regarding the issues explored. The core questions of the interviews attempted to reveal the goals, internal processes, values, and interests of the researched groups.

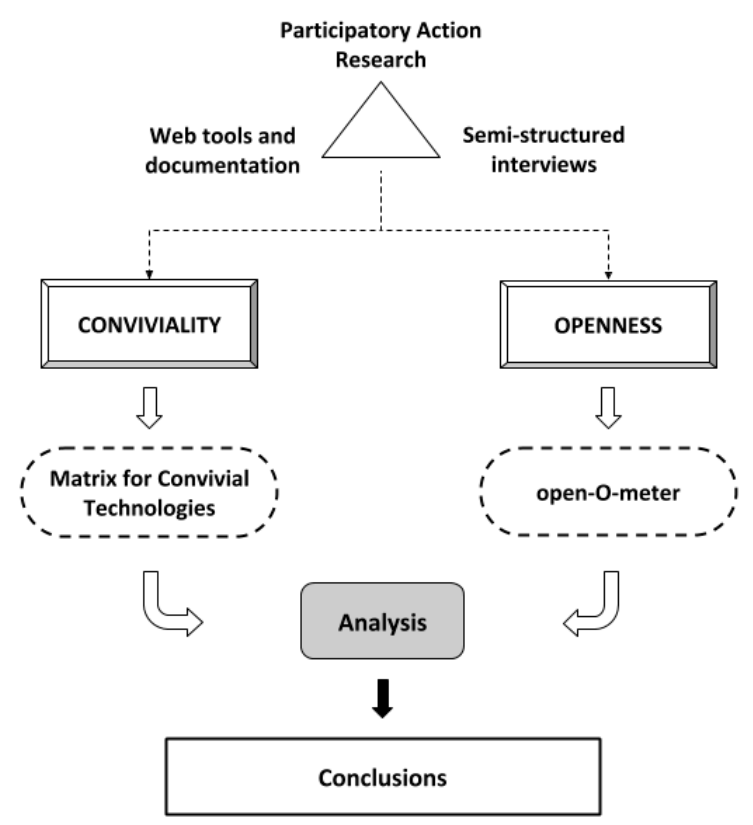

Figure 1. Research framework.

Additionally, a participatory action research approach [41,42] was utilized to provide experiential insight into the construction of a WikiHouse through collaborative processes. Field observations were conducted at Minitopia Poeldonk, where the WikiHouse Den Bosch will be placed once completed. During the aforementioned period of stay in the Netherlands, one of the authors assisted in the construction of the WikiHouse Den Bosch, where interaction with members of the case study took place on-site, attaining a more unobstructed view of the internal processes of the groups observed [39]. While one of the authors actively participated in the development of the selected case study and provided critical checks regarding the responses of the community members, to avoid bias and preconceived notions, the other author critically examined the overall process.

Furthermore, digital web tools and other documentation were also used for triangulation [43]. Online platforms, discussion sections, and available forums as well as email communications with individuals from the case study were utilized for data gathering. Several documentation tools and 
sources including reports, articles, audio-visual material, and blog posts were easily accessed due to the openness element that permeates open source initiatives.

In this paper, the conviviality and the openness aspect of the WikiHouse were explored through a case-study by utilizing two tools (Figure 1): a qualitative one (the matrix of convivial technology, $\mathrm{MCT}$ ) and a quantitative one (the open-O-meter). The former was used to discuss the WikiHouse technology in a structured manner, highlighting the importance of the social construction of technology. By empirically assessing Illich's theory on conviviality, the matrix of convivial technology has been developed, enabling the self-assessment of groups that use or adapt technology towards a social, economic, and ecological transformation [30].

The MCT includes the four life-cycle levels: material, production, use, and infrastructure. Each of these levels is correlated with five dimensions that define convivial technologies based on the group's values and practices. These dimensions are (i) relatedness, which refers to the human capability to relate to others; (ii) accessibility, which answers the question of who, where, and how can build or use a technology; (iii) adaptability, which explores someone's willingness to be independent (through the concepts of modularity and scalability) or linked; (iv) bio-interaction, referring to the usefulness of the produced materials for the living organisms; and (v) appropriateness, which correlates the input and output considering the local context. Although the MCT was developed so that it could cover a wide range of technologies, each technology needs to be adapted to the local needs. Thus, the MCT was developed in word-pairs including antagonistic terms that can be omitted and/or adapted to the users' needs (see Appendix A).

The second tool used, the open-O-meter [44], refers to the degree of openness of the WikiHouse technology, which enables its democratization and widespread replicability [45]. It is a simple quantitative tool that uses eight criteria to calculate the openness index of a technology. These criteria include the publication of the design files, assembly instructions, a bill of materials, the availability of all of the information in an editable format, a contribution guide, and the free distribution of this information under a license allowing commercial reuse [44]. If a product fulfills all of these criteria, its openness index equals eight (see Appendix A).

\subsection{The WikiHouse Den Bosch}

Across a broad spectrum of open construction systems, the WikiHouse project was selected. The latter allows for the production of modular, lightweight, and structurally-robust buildings through its Wren chassis system (Figure 2). It was initiated in 2011 by Alastair Parvin and Nick Ierodiaconou as an innovative way of designing and sharing construction packages online [46]. The power of the WikiHouse rests on its ability to globally share designs, while testing, improving, and enriching knowledge via digital fabrication tools. All this information is maintained by a non-profit legal entity based in the UK, the WikiHouse Foundation, which aims to promote collaboration and create feedback loops among the ever-growing global WikiHouse community [46]. 


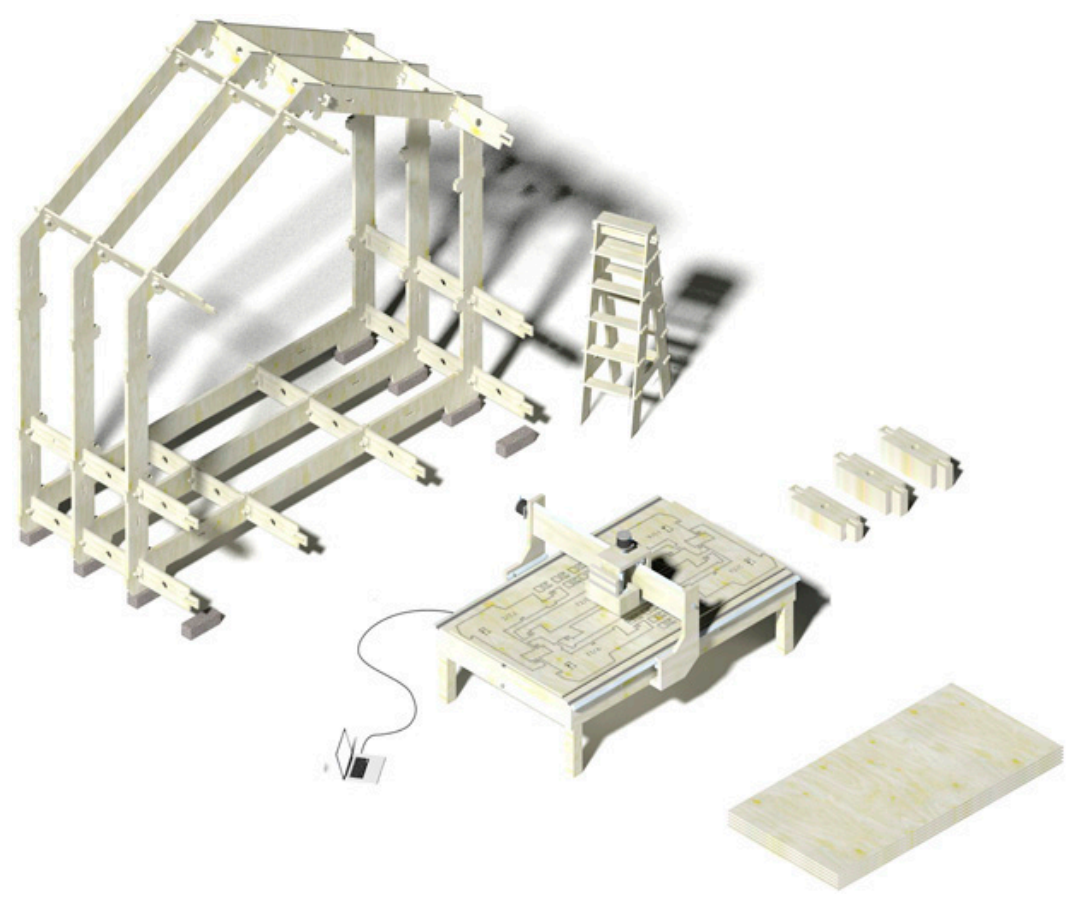

Figure 2. The WikiHouse building parts (Wikiparts). Source: WikiHouse.cc.

The expansion of the WikiHouse project renders it a popular construction system in the Western and non-Western world [47]. Our research focused on the Netherlands due to ongoing local activities related to WikiHouse development. Following the growing demand for affordable housing, several WikiHouse initiatives have emerged in the country, ranging from individual houses to collective efforts on a larger scale. Such initiatives are supported by the WikiHouseNL Foundation, the Dutch department of the WikiHouse Foundation [46].

For instance, the Woningbouwatelier ("housing atelier") in Almere brings together new concepts, knowledge, and experience of innovative parties in the field of housing. The goal is to produce WikiHouse buildings that can be easily assembled by non-experts that conform to the local building codes [48]. Another example is that of Minitopia in 's-Hertogenbosch (colloquially known as Den Bosch), where experimental forms of housing including a WikiHouse are being developed as a response to the high housing demand [49].

Minitopia was launched in 2016 in 's-Hertogenbosch by Rezone, an initiative that develops projects at the intersection of architecture and art. Minitopia aims to create small, temporary, cheap, and sustainable houses with increased citizen engagement [50]. At first, Minitopia was located at Eekbrouwersweg, using a property owned by the housing corporation Zayaz. In June 2018, Minitopia moved to Poeldonk, an industrial estate owned by the Municipality of 's-Hertogenbosch. This new location can host up to 25 temporary houses that residents will build in part or entirely by themselves and may use for a maximum of five years (Figure 3). 


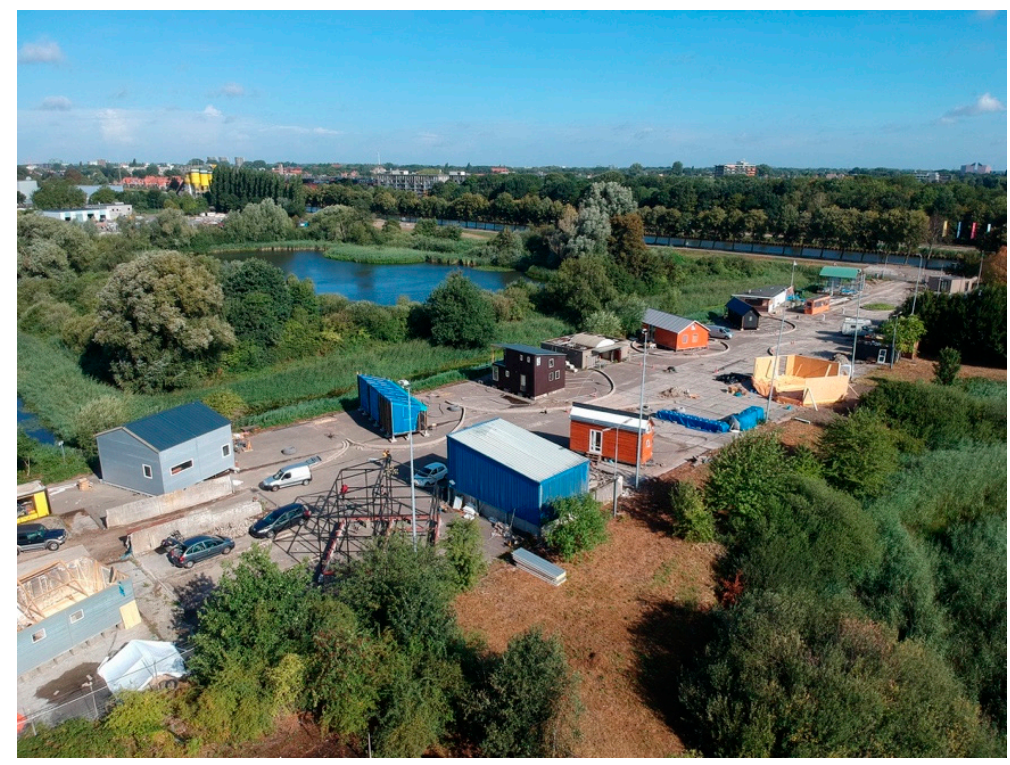

Figure 3. The Minitopia Poeldonk area. Source: Tessa Peters and Rolf van Boxmeer.

Patricia Sips was one of the five tenants allowed by Zayaz to build their own home in Minitopia. She opted for the WikiHouse, and like all participants in Minitopia, she received a residents' budget to bring her ideas to life with the help of volunteers around the globe. Her initiative was called WikiHouse Den Bosch (Figure 4).

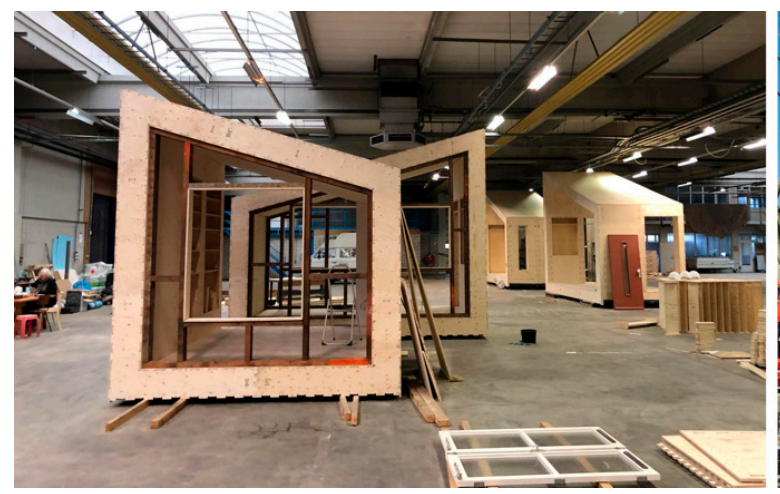

(A)

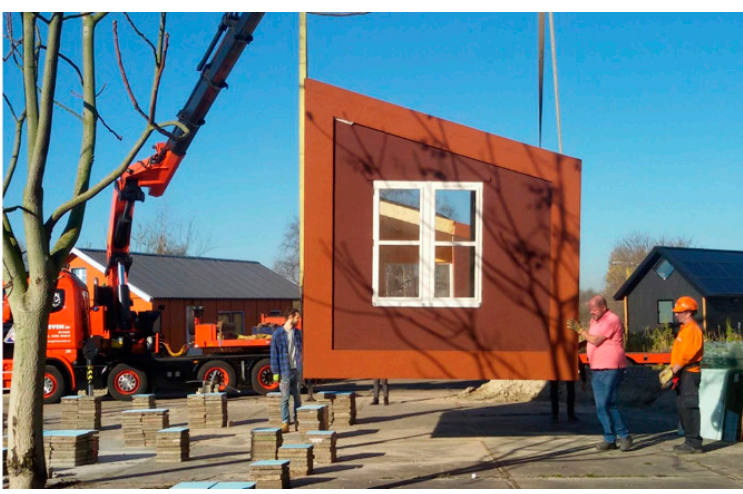

(B)

Figure 4. (A) Constructing the WikiHouse den Bosch. Source Tessa Peters and Rolf van Boxmeer; (B) Placing the WikiHouse Den Bosch. Source: Tessa Peters and Rolf van Boxmeer.

Its construction began in September 2018 and it finally opened its doors in March 2019 [51]. The community of contributors consisted of 22 people, aged between 25 to 65 years old. Five were consistent members throughout the construction process, while the rest of the contributors spent from three to 30 days. The gender balance was equally divided between females and males. In terms of the available expertise, it ranged from artists to business consultants, teachers, and engineers including both university students and retirees.

The design of the WikiHouse Den Bosch was developed by both Rezone and Patricia Sips [52]. Two main aspects were taken into account: (i) design for modularity (four distinct units could be combined, taken apart, and transported separately); and (ii) design for sustainability (second-hand and reusable materials were preferred). Special attention was paid to increase energy-efficiency and affordability. Hence, a 44 square-meter structure was built (Figure 5) that cost less than 38,000 euros [52]. 


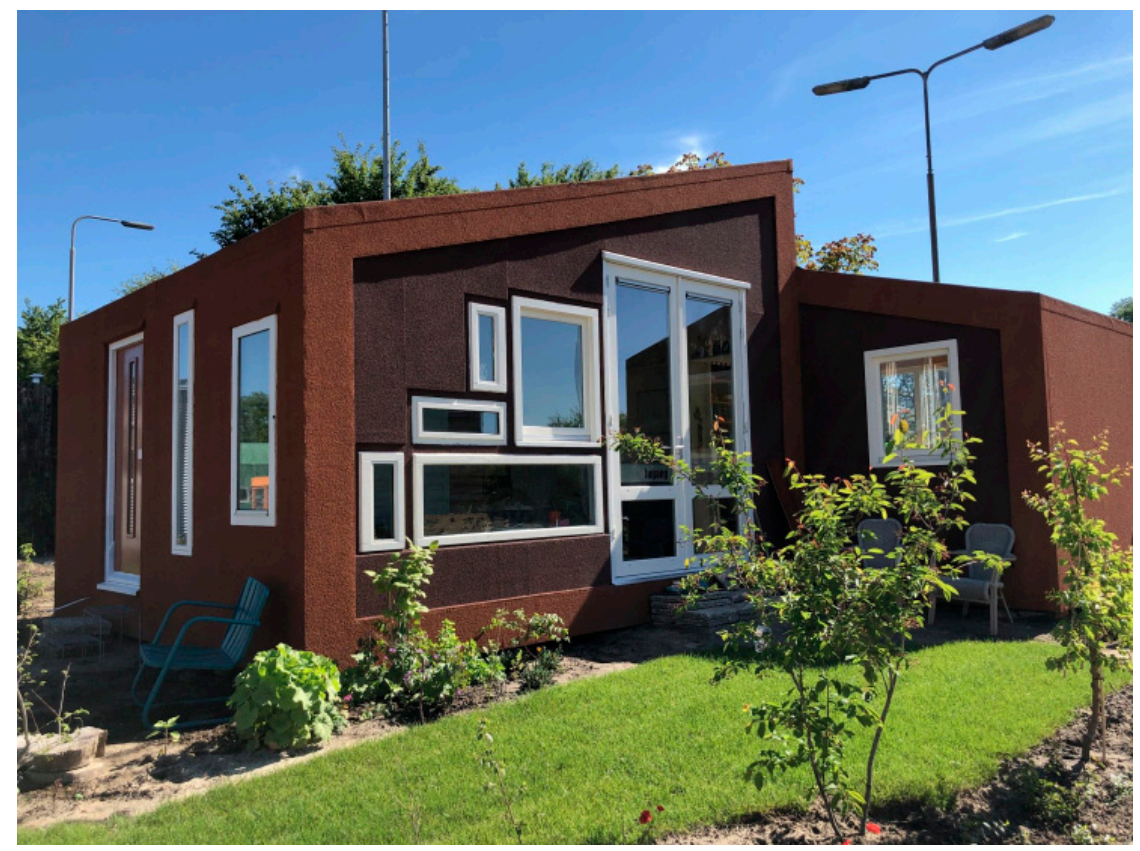

Figure 5. The WikiHouse Den Bosch. Source: Tessa Peters and Rolf van Boxmeer.

\section{Analysis}

In this section, the conviviality and openness potential of the WikiHouse Den Bosch are discussed. The analysis refers to the WikiHouse as a complete house to live in including building structure and utilities. We will first elaborate on the conviviality potential through the examination of the MCT's responses and then critically discuss the openness aspect based on the open-O-meter tool.

\subsection{The Conviviality Aspect}

The assessment of the WikiHouse's conviviality was facilitated through the use of a range of values attributed to the antagonistic terms of the matrix. To fit the specific characteristics of our case, the MCT was simplified by erasing certain pairs of antagonistic terms (see the original and the adapted MCT table in Appendix A).

The MCT was filled in by 10 people who contributed to the construction of the WikiHouse Den Bosch. The selected group can be considered as a representative sample since it reflects the main characteristics of the overall community. More specifically, the age range was similar ( 25 to 65 years), the gender balance was equally distributed and most of the respondents had a non-engineering background (see Appendix B).

The analysis followed the four life-cycle levels identified in the MCT (i.e., materials, production, use, infrastructure). To begin with, the respondents mentioned that the materials were easily accessible through various sources. Furthermore, it was possible to choose out of a variety of materials according to local needs and conditions. Regarding the cost of the materials, the responses were divergent due to the subjectivity of the question. Since the origins of the respondents varied, different answers were received; most of them deemed it to be of low-cost whereas others found it cost-intensive. Considering the Dutch context, the construction was deemed affordable. The tools needed for the processing of materials were characterized either as specialized (by non-engineers) or everyday tools (by engineers), based on the skills of each respondent. The presence of engineers among the contributors was important in overcoming obstacles during the construction. Additionally, all respondents highlighted the necessity of having access to a CNC machine. Finally, although the WikiHouse Den Bosch was built out of reused and easily recyclable materials, there were toxic emissions related to the processing of materials. 
The production phase was seen as a collaborative and constructive process that allowed for joyful work. Contributing to the assembly of the Wikiparts was easy since no special tools were needed. The assembly could take place asynchronously and autonomously, thanks to the appropriate instructions and detailed designs provided by the architects of the project. Dismantling the parts of a house once finished is difficult, but life-time changes rarely demand it. However, the addition of new parts according to the users' needs is possible. These characteristics designate the WikiHouse as a modular structure. Despite the some waste emissions, there was no significant environmental impact during the production phase.

Regarding the use level, the respondents described the WikiHouse Den Bosch as "usable by anyone", since it fulfills the basic needs of the user and provides flexibility in selecting the infrastructure. Concerning its maintenance, the WikiHouse Den Bosch was characterized as "repairable by some". Although it was argued that most of the parts could be repaired quickly, additional skills may be needed to maintain certain infrastructure such as plumbing. The need for experts within the community seems to be vital for maintaining both the WikiHouse structure as well as the community itself. The fixed costs are not significantly decreased due to the installed energy and water systems. No solar panels or water reuse systems are available at the WikiHouse Den Bosch due to time and cost limitations.

Furthermore, issues associated with safety checks and local regulations need to be addressed by the users. In the case of the WikiHouse Den Bosch, the structure was exempt from the need to conform to the local building codes due to its experimental and temporary character. In addition, the WikiHouse Den Bosch was understood as a locally operable construction that could be easily adapted to the local setting. Nevertheless, following the respondents' feedback, the durability of the structure was not ensured.

Finally, a common element present throughout all phases was the increased community engagement that was enabled by the nature of the project. Collaboration and sharing were promoted, which allowed for the development of friendship and feelings of being useful.

\subsection{The Openness Aspect}

This assessment refers to information such as designs, CAD files, bill of materials, and assembly instructions. A web-based repository such as GitHub is used for file sharing in most WikiHouse projects. However, fragmentation issues arise since there is not a comprehensive online platform used by all communities that develop WikiHouses globally. Contrary to software components, sufficiently documenting a piece of hardware is challenging [3]. Problems pertain to the documentation adequacy of the WikiHouse solutions, and the ease in tracking the relevant information [53]. Consequently, concerns have been raised with regard to the openness degree of hardware solutions like the WikiHouse.

A first attempt in filling the open-O-meter for the WikiHouse concept was realized in the context of a French-German research project called OPEN! - Methods and tools for community-based product development [54]. Following this assessment, the WikiHouse was rated five out of eight. The missing points were due to the provision of non-editable assembly instructions, a non-editable published bill of materials, and the lack of a published contribution guide.

However, apart from the open-O-meter evaluation via simple binary criteria, the quality of the published documentation of each WikiHouse project should be examined. The comprehensiveness and clarity of the published information increase the replicability and diffusion of the product. Thus, our contribution was to critically examine and enrich the existing assessment of the WikiHouse's openness based on the expertise of three main stakeholders of the WikiHouseNL Foundation (see Appendix B).

First, concerning the publication of the design files, the interviewees agreed that many WikiHouse design files were shared on GitHub in different stages of construction. However, most of them were uncategorized and not engineered. The respondents mentioned that when private companies were involved, the publication of all designs was not assured. For instance, although most of the WikiHouse Den Bosch designs were published in an editable format, those related to its structural analysis were not 
shared. In addition, the modification of existing designs may be more time-consuming than drawing new ones.

Detailed manuals with the assembly instructions are available on Github. For the editability of the instructions, Tessa and Rolf mentioned that they decided to draw new manuals since the original model could not be easily modified for the needs of the WikiHouse Den Bosch. Vincent stressed the importance of being an experienced user in dedicated software to fork the assembly instructions.

Regarding the bill of materials, the publication of information for the whole building depends on the parties involved. For instance, the bill of materials can be obtained for the structural components of the WikiHouse, but not the cost-related data of the building. Acquiring a complete bill of materials for a WikiHouse is complicated, since it depends on the local needs and conditions. Although such a bill of materials for a WikiHouse does not exist, Open System Labs [55] is currently working on a platform for sharing customizable designs with detailed descriptions of the materials (including economic data, energy, and environmental factors).

Furthermore, a contribution guide should be provided through transparent processes to enable the unconditional participation of individuals. Considering the uniqueness of a WikiHouse project, each one has guidelines that should fit the local needs and regulations. In the case of the WikiHouse Den Bosch, the instigator provided conditions for participation in the construction process that were readapted regularly to serve the changing needs of the project [56].

The licensing guidelines [57] of the first WikiHouse building type (i.e., the Microhouse [58]) indicate that the published content can be shared and adapted, even for commercial use. The latest version of this license, Attribution-ShareAlike 4.0 International: CC BY-SA 4.0, was used in the WikiHouse Den Bosch case [59].

In all, it becomes evident that every WikiHouse initiative is unique and should be evaluated based on its distinctive characteristics and rules. Following the responses of the interviewees, the WikiHouse Den Bosch scored six out of eight since it lacked editable assembly instructions and an editable published bill of materials. Nevertheless, although some of the open-O-meter factors received a positive degree, critical issues should be addressed to enhance the diffusion and replication of the WikiHouse technology.

\section{Conclusions}

Both conviviality and openness are ambiguous terms. Whether an artifact is convivial or open is not a binary decision. Instead, there is a spectrum and degree of each of these aspects that characterizes a technological artifact. For instance, defining conviviality and openness may be easier when engaging with software or low-tech products than high-tech hardware.

The WikiHouse Den Bosch is a sophisticated construction that consists of different parts and requires certain skills for its construction and maintenance. The conviviality potential of such a complex artifact ends up being subjective. Based on our results, it is evident that the level of the respondent's expertise is crucial when assessing conviviality. The potential lack of certain skills needed to manufacture or maintain an artifact could lower the artifact's conviviality. However, the existence of a community around that artifact could possibly alleviate this issue via the diffusion of knowledge amongst its members.

Furthermore, the available expertise of the contributors allows for enhanced autonomy in both the construction and maintenance stages. In this sense, conviviality is stronger at the collective level than at the individual one. Additionally, openness adds to the conviviality potential of the project, thus boosting the autonomy on all levels by providing access to relevant information.

The aforementioned potential is arguably linked to the attributes observed in the DGML approach. In an attempt to generalize the conviviality of DGML artifacts, we proposed achieving "institutionalized conviviality" through more structured processes. For instance, modularity can be considered as a characteristic that could reduce the complexity of artifacts. In addition, standardization of the design 
parts as well as the existence of detailed open-source documentation could facilitate the replicability of open hardware solutions through comprehensive manuals.

Overall, however, DGML artifacts may be quite varied in their conception and development, so the community aspect is crucial. Once there is an engaged community with a strong supporting network, the level of conviviality may be high, despite potential complexities that would otherwise hinder it. Nevertheless, given that such projects are driven by specific local or regional socio-economic and political characteristics and goals, the generalizability of our conclusions is confined. Hence, further research should focus on different contexts, locations, and artifacts to provide a wider understanding of the understudy phenomenon. Finally, a comparison of an industrially produced house and an open construction system through technical evaluations such as the life cycle assessment would be valuable.

Author Contributions: Conceptualization, C.P. and V.N.; Data curation, C.P. and V.N.; Formal analysis, C.P. and V.N.; Funding acquisition, C.P.; Investigation, C.P.; Methodology, C.P. and V.N.; Project administration, C.P.; Resources, C.P. and V.N.; Software, C.P. and V.N.; Supervision, V.N.; Validation, C.P.; Visualization, V.N.; Writing-original draft, C.P. and V.N.; Writing-review and editing, C.P. and V.N.

Funding: This paper is part of a project that has received funding from the European Research Council (ERC) under the European Union's Horizon 2020 research and innovation programme (grant agreement No 802512). Furthermore, the first author was funded through the COST Action CA16121 to conduct fieldwork in the Netherlands.

Acknowledgments: The authors would like to especially thank Patricia Sips for her hospitality and support throughout our research as well as Vincent Muller, Rolf van Boxmeer, and Tessa Peters for discussions regarding technical descriptions of the WikiHouse technology. Permission for the use of all figures was granted by the respective copyright holders.

Conflicts of Interest: The authors declare no conflict of interest. The funders had no role in the design of the study; in the collection, analyses, or interpretation of data; in the writing of the manuscript, or in the decision to publish the results.

\section{Appendix A}

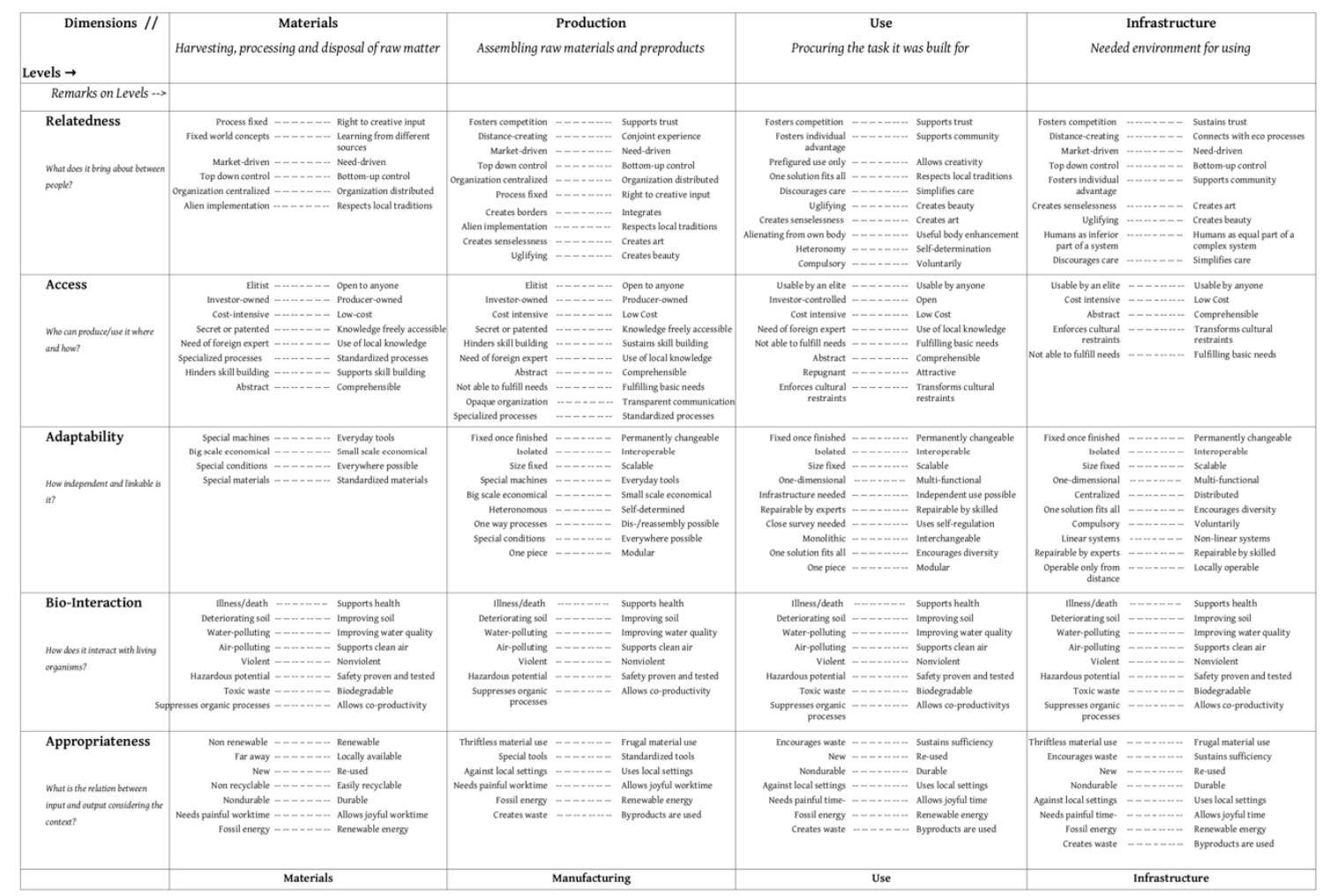

Figure A1. The original version of the matrix of convivial technologies (MCT). 


\begin{tabular}{|c|c|c|c|c|}
\hline $\begin{array}{l}\text { Dimensions // } \\
\text { Levels } \rightarrow\end{array}$ & $\begin{array}{l}\text { Materials } \\
\text { Harvesting, processing and } \\
\text { disposal of raw matter }\end{array}$ & $\begin{array}{l}\text { Production } \\
\text { Assembling raw materials and preproducts }\end{array}$ & $\begin{array}{c}\text { Use } \\
\text { Procuring the task it was built for }\end{array}$ & $\begin{array}{c}\text { Infrastructure } \\
\text { Needed environment for using }\end{array}$ \\
\hline \multicolumn{5}{|l|}{ Remarks on Levels -.> } \\
\hline $\begin{array}{l}\text { Relatedness } \\
\text { What does it bring about } \\
\text { between people? }\end{array}$ & 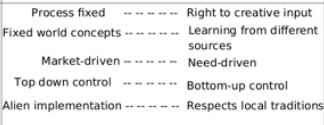 & 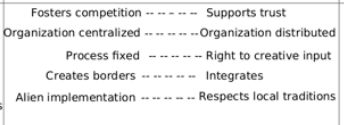 & 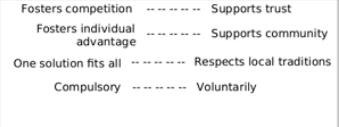 & 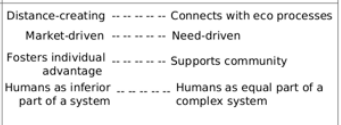 \\
\hline $\begin{array}{l}\text { Access } \\
\text { Who can produce/use it. } \\
\text { where and how? }\end{array}$ & 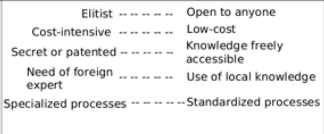 & 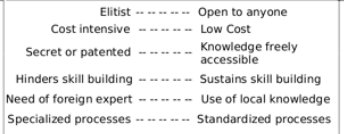 & 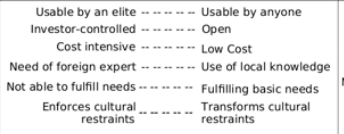 & 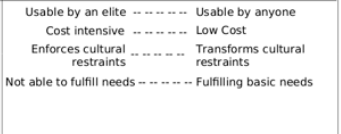 \\
\hline $\begin{array}{l}\text { Adaptability } \\
\text { How independent and } \\
\text { linkable is ity? }\end{array}$ & $\begin{array}{l}\text { Special machines …....... Everyday tools } \\
\text { Special conditions …...... Everywhere possible } \\
\text { Special materials }\end{array}$ & 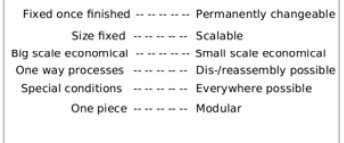 & 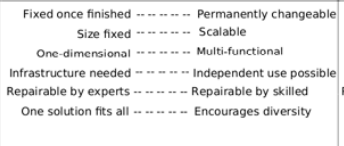 & 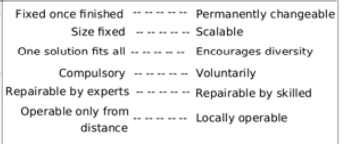 \\
\hline $\begin{array}{l}\text { Bio-Interaction } \\
\text { How does it interact with } \\
\text { living organisms? }\end{array}$ & 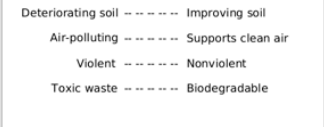 & 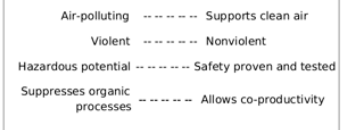 & 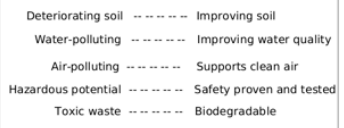 & 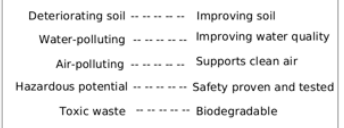 \\
\hline Appropriateness & 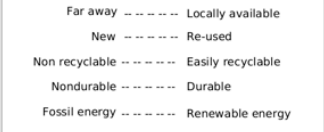 & 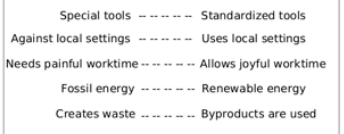 & 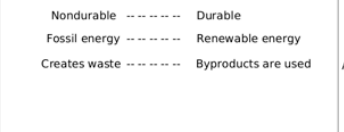 & 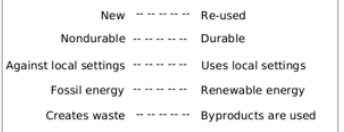 \\
\hline & Materials & Manufacturing & Use & Infrastructure \\
\hline
\end{tabular}

Figure A2. The modified version of the MCT.

Table A1. The open-O-meter tool.

open-O-meter

Which sources have you opened?

Are the design files published?

3

4

5

6

7

8

Technical components of the product are publicly available (CAD-files, computer code etc.)

Are the assembly instructions published? Instructions for how to assemble are quickly available

Is the bill of materials published?

The product's bill of material is publicly available

Is the contributing guide published?

A guide for how users can contribute is available

Are the published design files in editable formats?

One or more of the file formats used is in editable format

Are the published assembly instructions in editable formats?

The assembly instructions are published in editable format

Is the published bill of materials in editable format?

The bill of materials is published in editable format

Is all this information published under a license allowing commercial reuse?

An open source license is used that allows users to commercially reuse the product 


\section{Appendix B}

Table A2. List of names, gender, expertise, and roles of the contributors to the MCT.

\begin{tabular}{cccc}
\hline Respondents & Gender & Expertise & Engagement in the Construction \\
\hline Respondent 1 (Instigator) & $\mathrm{F}$ & Art therapist & Consistent \\
Respondent 2 (Adviser) & $\mathrm{M}$ & Project manager & Consistent \\
Respondent 3 & $\mathrm{F}$ & Social worker & Consistent \\
Respondent 4 & $\mathrm{~F}$ & Engineer & Occasional \\
Respondent 5 & $\mathrm{M}$ & Business consultant & Occasional \\
Respondent 6 & $\mathrm{~F}$ & HR specialist & Occasional \\
Respondent 7 & $\mathrm{~F}$ & Artist & Occasional \\
Respondent 8 & $\mathrm{M}$ & Teacher & Consistent \\
Respondent 9 & $\mathrm{M}$ & Economist & Occasional \\
Respondent 10 & $\mathrm{M}$ & Engineer & Consistent \\
\hline
\end{tabular}

Table A3. List of names, gender, expertise, and roles of the contributors to the open-O-meter.

\begin{tabular}{cccc}
\hline Respondents & Gender & Expertise & Organization/Project \\
\hline Vincent Muller & $\mathrm{M}$ & Architect & Co-founder of WikiHouseNL Foundation, WIkiHouse in Almere \\
Rolf van Boxmeer & $\mathrm{M}$ & Architect & Co-designer of WikiHouse Den Bosch/Minitopia \\
Tessa Peters & $\mathrm{F}$ & Architect & Co-designer of WikiHouse Den Bosch/Minitopia \\
\hline
\end{tabular}

\section{References}

1. Benkler, Y. The Wealth of Networks: How Social Production Transforms Markets and Freedom; Yale University Press: New Haven, CT, USA, 2006.

2. Bauwens, M. The political economy of peer production. Post-Autistic Econ. Rev. 2006, 37, 33-44.

3. Balka, K.; Raasch, C.; Herstatt, C. The effect of selective openness on value creation in user innovation communities. J. Prod. Innov. Manag. 2013, 31, 392-407. [CrossRef]

4. Kohtala, C.; Hyysalo, S. Anticipated environmental sustainability of personal fabrication. J. Clean. Prod. 2015, 99, 333-344. [CrossRef]

5. Niaros, V. Introducing a taxonomy of the "smart city": Towards a commons-oriented approach? tripleC 2016, 14, 51-61. [CrossRef]

6. Niaros, V.; Kostakis, V.; Drechsler, W. Making (in) the smart city: The emergence of makerspaces. Telemat. Inform. 2017, 34, 1143-1152. [CrossRef]

7. Troxler, P. Libraries of the peer production era. In Open Design Now: Why Design Cannot Remain Exclusive; Van Abel, B., Evers, L., Klaassen, R., Troxler, P., Eds.; BIS Publishers: Amsterdam, The Netherlands, 2011; pp. 86-95.

8. Kostakis, V.; Niaros, V.; Dafermos, G.; Bauwens, M. Design global, manufacture local: Exploring the contours of an emerging productive model. Futures 2015, 73, 126-135. [CrossRef]

9. Kostakis, V.; Liarokapis, M.; Latoufis, K.; Bauwens, M. The convergence of digital commons with local manufacturing from a degrowth perspective: Two illustrative cases. J. Clean. Prod. 2016, 197, 1684-1693. [CrossRef]

10. Bonvoisin, J.; Mies, R.; Boujut, J.F.; Stark, R. What is the "source" of open source hardware? J. Open Hardw. 2017, 1, 5. [CrossRef]

11. U.S. Green Building Council. Buildings and Climate Change; U.S. Green Building Council: Washington, DC, USA, 2018. Available online: http://www.eesi.org/files/climate.pdf (accessed on 5 August 2019).

12. Priavolou, C. The emergence of open construction systems: A sustainable paradigm in the construction sector? J. Futures Stud. 2018, 23, 67-84.

13. Kostakis, V. How to reap the benefits of the "digital revolution"? Modularity and the commons. Halduskultuur 2019, in press.

14. Stake, R. The Art of Case Study Research; Sage: Thousand Oaks, CA, USA, 1995.

15. Parvin, A. Architecture (and the other 99\%): Open-source architecture and design commons. Archit. Des. 2013, 83, 90-95. [CrossRef] 
16. Kohtala, C. Addressing sustainability in research on distributed production: An integrated literature review. J. Clean. Prod. 2015, 106, 654-668. [CrossRef]

17. Benkler, Y.; Shaw, A.D.; Hill, B.M. Peer production: A modality of collective intelligence. In Handbook of Collective Intelligence; Malone, T.W., Bernstein, M.S., Eds.; MIT Press: Cambridge, MA, USA, 2015; pp. 175-203.

18. Illich, I. Energy and Equity; Calder and Boyars: London, UK, 1974.

19. March, H.; Ribera-Fumaz, R. Smart contradictions: The politics of making Barcelona a self-sufficient city. Europ. Urb. Reg. Stud. 2016, 23, 816-830. [CrossRef]

20. Illich, I. Tools for Conviviality; Fontana/Collins: Glasgow, Scotland, 1973.

21. Bijker, W.E. Of Bicycles, Bakelites, and Bulbs: Toward a Theory of Socio-Technical Change; MIT Press: Cambridge, MA, USA, 1997.

22. Latour, B. We Have Never Been Modern; Harvard University Press: Cambridge, MA, USA, 1993.

23. Bradley, K. Bike kitchens: Spaces for convivial tools. J. Clean. Prod. 2018, 197, 1676-1683. [CrossRef]

24. March, H. The smart city and other ICT-led techno-imaginaries: Any room for dialogue with degrowth? J. Clean. Prod. 2018, 197, 1694-1703. [CrossRef]

25. Lizarralde, I.; Tyl, B. A framework for the integration of the conviviality concept in the design process. J. Clean. Prod. 2017, 197, 1766-1777. [CrossRef]

26. Samerski, S. Tools for degrowth? Ivan Illich's critique of technology revisited. J. Clean. Prod. 2018, 197, 1637-1646. [CrossRef]

27. Mies, R.; Bonvoisin, J.; Jochem, R. Harnessing the synergy potential of open source hardware communities. In Co-Creation: Reshaping Business and Society in the Era of Bottom-Up Economics; Redlich, T., Moritz, M., Wulfsberg, J.P., Eds.; Springer: Berlin, Germany, 2018; pp. 129-145.

28. Giotitsas, C. Open Source Agriculture: Grassroots Technology in the Digital Era; Palgrave Macmillan: Basingstoke, UK, 2019.

29. MacKenzie, D.; Wajcman, J. The Social Shaping of Technology; Open University Press: Milton Keynes, UK, 1985.

30. Vetter, A. The matrix of convivial technology: Assessing technologies for degrowth. J. Clean. Prod. 2018, 197, 1778-1786. [CrossRef]

31. Von Hippel, E. Comment on is open innovation a field of study or a communication barrier to theory development? Technovation 2010, 30, 555. [CrossRef]

32. Aitamurto, T.; Holland, D.; Hussain, S. The open paradigm in design research. Des. Issues 2015, 31, 17-29. [CrossRef]

33. Maxwell, E. Open standards, open source, and open innovation: Harnessing the benefits of openness. Innov. Tech. Gov. Glob. 2006, 1, 119-176. [CrossRef]

34. Baldwin, C.; von Hippel, E. Modeling a paradigm shift: From producer innovation to user and open collaborative innovation. Organ. Sci. 2011, 22, 1399-1417. [CrossRef]

35. Raasch, C.; Herstatt, C. Product development in open design communities: A process perspective. Inter. J. Innov. Tech. Manag. 2011, 8,557-575. [CrossRef]

36. Lakhani, K.; Wolf, R. Why hackers do what they do: Understanding motivation and effort in free/open source software projects. In Perspectives on Free and Open Source Software; Feller, J., FitzGerald, B., Hissam, S., Lakhani, K., Eds.; MIT Press: Cambridge, MA, USA, 2005.

37. Thorne, M.; Openwashing. Michelle Thorne 2019. Available online: https://michellethorne.cc/2009/03/ openwashing/ (accessed on 5 August 2019).

38. Wiley, D.; The Consensus Around “Open”. Open Content 2016. Available online: https://opencontent.org/ blog/archives/4397 (accessed on 5 August 2019).

39. Yin, R.K. Case Study Research: Design and Methods; Sage: Thousand Oaks, CA, USA, 2003.

40. Rieger, J.H. Key informant. In Blackwell Encyclopedia of Sociology; Ritzer, G., Ed.; Blackwell: Malden, MA, USA, 2007.

41. MacDonald, C. Understanding participatory action research: A qualitative research methodology option. Can. J. Action Res. 2012, 13, 34-50.

42. McTaggart, R. Participatory Action Research; State University of New York Press: New York, NY, USA, 1997.

43. Murthy, D. Digital ethnography: An examination of the use of new technologies for social research. Sociology 2008, 42, 837-855. [CrossRef]

44. Open-O-Meter. OPEN! 2017. Available online: https://opensourcedesign.cc/wiki/index.php/Open-O-meter (accessed on 5 August 2019). 
45. Bonvoisin, J. Implications of open source design for sustainability. In Smart Innovation, Systems and Technologies; Setchi, R., Howlett, R.J., Liu, Y., Theobald, P., Eds.; Springer: Berlin, Germany, 2016; pp. 49-59.

46. WikiHouseNL. Available online: https://wikihousenl.cc/stichtingwhnl/ (accessed on 5 August 2019).

47. Knight, H. An Incomplete List of Complete WikiHouse Projects. Available online: https://medium.com/ wikihouse-stories/an-incomplete-list-of-wikihouse-projects-bf934c29ed04 (accessed on 5 August 2019).

48. De Architect. Almere en Rijk Starten Woningbouwatelier. Available online: https://www. dearchitect.nl/architectuur/nieuws/2014/02/almere-en-rijk-starten-woningbouwatelier-101122695 (accessed on 5 August 2019).

49. Minitopia. Minitopia Poeldonk. Available online: http://www.minitopia.eu/ (accessed on 5 August 2019).

50. Van de Ven, J. Maximaal vijf jaar Minitopia in de Poeldonk met 25 woningen. Available online: https://www.bd. nl/s-hertogenbosch/maximaal-vijf-jaar-minitopia-in-de-poeldonk-met-25-woningen \{\}a9675ec8/ (accessed on 5 August 2019).

51. Den Bosch Nieuws. Opening Eerste Bewoonde Wikihouse van Nederland! Available online: https://den-bosch. nieuws.nl/nieuws/85792/opening-eerste-bewoonde-wikihouse-van-nederland/ (accessed on 5 August 2019).

52. Minitopia. WikiHouse. Available online: http://www.minitopia.eu/bewoners-en-hun-droomhuizen.html\# wikihouse (accessed on 5 August 2019).

53. Bonvoisin, J.; Mies, R. Measuring openness in open source hardware with the open-O-meter. Procedia CIRP 2018, 78, 388-393. [CrossRef]

54. OPEN! List of Open Source Hardware Products. Available online: https://opensourcedesign.cc/wiki/index. php/List_of_open_source_hardware_products (accessed on 5 August 2019).

55. Open System Labs. Available online: https://www.opensystemslab.io/ (accessed on 5 August 2019).

56. Wikihouse Den Bosch. Helpende Handen. Available online: https://wikihousedenbosch.com/helpendehanden/ (accessed on 5 August 2019).

57. Creative Commons. Available online: https://creativecommons.org/licenses/by-sa/3.0/ (accessed on 5 August 2019).

58. MicroHouse. Available online: https://wikifab.org/wiki/MicroHouse (accessed on 5 August 2019).

59. Creative Commons License. Available online: https://creativecommons.org/licenses/by-sa/4.0/ (accessed on 5 August 2019).

(C) 2019 by the authors. Licensee MDPI, Basel, Switzerland. This article is an open access article distributed under the terms and conditions of the Creative Commons Attribution (CC BY) license (http://creativecommons.org/licenses/by/4.0/). 